Article

\title{
Adaptability of Populus to Physiography and Growing Conditions in the Southeastern USA
}

\author{
Solomon B. Ghezehei ${ }^{1, * \mathbb{C}}$, Elizabeth G. Nichols ${ }^{1}$, Christopher A. Maier ${ }^{2}$ and Dennis W. Hazel ${ }^{1}$ \\ 1 Department of Forestry \& Environmental Resources, NC State University, Raleigh, NC 27695, USA; \\ egnichol@ncsu.edu (E.G.N.); hazeld@ncsu.edu (D.W.H.) \\ 2 Southern Research Station, USDA Forest Service, Research Triangle Park, NC 27709, USA; cmaier@fs.fed.us \\ * Correspondence: sbghezeh@ncsu.edu; Tel.: +1-919-513-1371
}

Received: 22 December 2018; Accepted: 30 January 2019; Published: 2 February 2019

\begin{abstract}
Populus species have a high productivity potential as short-rotation woody crops, provided that site-suitable varieties are planted. The Coastal Plain, the Piedmont, and the Blue Ridge Mountains make up a significant part of the eastern and southeastern USA, and an insight into poplar productivity and adaptability will be valuable for the successful implementation of large-scale poplar stands in these regions. The objectives of this study were to examine the green wood biomass (hereafter biomass), biomass allocation, and wood properties of poplars in relation to growing conditions, physiography, and topography. The biomass of 4-year-old poplars was estimated using an equation derived through destructive sampling. Biomass-based clonal rankings were compared across the various site conditions (fertility, irrigation, land marginality, soil preparation, and topography) and the three physiographic provinces. Although not all clonal differences in biomass were significant, growing conditions, physiography, and soil preparation affected the clonal rankings and the significance of the clonal differences. Biomass changes due to physiography and land conditions were more structured at the genomic-group level. A higher-altitude physiography led to greater biomass increases in Populus trichocarpa $\times$ Populus deltoids (TD) clones than in P. deltoids $\times$ P. deltoids (DD) clones and vice versa. Favorable soil quality or management generally led to greater biomass of DD clones than of TD and P. deltoids $\times$ Populus maximowiczii (DM) clones. Weather-related variables were not clearly correlated with biomass, while land aspect was a significant influence on the biomass of genomic groups and clones. The site significantly affected wood density, moisture content, and carbon and nitrogen concentrations, while the clonal effects on wood composition and the clonal and site effects on biomass allocation were insignificant. Although clones showing greater biomass responses to growing conditions generally belonged to the same genomic group, clone-level selection could produce greater biomass gains than selection at the genomic-group level.
\end{abstract}

Keywords: biomass allocation; land marginality; Populus; physiographic provinces; soil preparation; topography; wood biomass productivity; wood composition and properties

\section{Introduction}

According to the 2005 Billion-Ton Study, the 2011 update, and the 2016 report, in the United States, woody feedstocks are expected to make a great contribution to the sustainable biomass supply for the bioeconomy [1]. However, with only $2 \%$ of the 2017 total energy consumption in the United States coming from wood and wood waste [2] and with the contribution of woody feedstocks to biofuels currently being non-existent for practical purposes, achieving the bioeconomy target will require a great enhancement in the productivity of woody crops [1]. In the southeastern United States, there is significant potential for conventional forestry to contribute to the bio-based economy mainly in the form of wood wastes and logging residues. However, a much greater potential lies in purpose-grown 
and fast-growing woody species in 'whole-tree' forms [1], also known as short-rotation woody crops (SRWCs).

The production of SRWCs is mainly restricted to marginal lands, including underutilized, reclaimed, and contaminated lands or lands that are poorly fertile for food production or convectional forestry. The marginality of lands varies greatly, and in the eastern and southeastern United States, the variations may be further emphasized by the variable and even contrasting physiographic features and growing conditions. Economic feasibility is key to the adoption of SRWCs and requires high productivity, suitable establishment, and high feedstock prices. It is important to assess and match SRWC species and varieties to particular site and growing conditions so as to maximize productivity. This has additional significance in the southeastern United States due to the standing of the region as the leading wood pellet exporter to Europe.

Poplars (Populus spp.) have great productivity potential as SRWCs nationally, provided that suitable clones are planted, and are one of the key non-coppice woody energy crop types identified in the Billion-Ton report [1]. Wood from poplars can be used for a number of applications, including the production of bioenergy, pulp, veneer, plywood, and timber [3,4]. Poplars can be grown in shorter rotations for bioenergy or pulp, or for up to 20 years when targeting high-value products [4,5].

Populus clones have been subjected to extensive studies in the United States since the 1920s and specifically in the southeast since the 1960s [6]. The adaptation of poplars to growing conditions is greatly dictated by, among other things, clone varieties and the quality of sites $[4,7]$. Moreover, previous studies involving multiple poplar clones and genotypes have shown great variations in clonal productivity [4,6,8-11]. Some of these studies have shown that genotype-environment interactions can affect poplar productivity $[9,11]$. The early results of a study comparing several Populus clones, native hardwoods, and eucalyptus species in the southeastern United States showed that Populus had superiority in growth and survival compared to other species [12]. Another early growth study indicated that although poplars can be highly productive, clonal and genotypic suitability to site conditions is a decisive consideration for its success as an SRWC [11].

An insight into poplar productivity and clonal and genotypic adaptability to growing conditions (site quality, land marginality, topography, and soil management) and physiography is crucial for identifying the best poplar varieties to grow under a particular set of conditions and for maximizing the efficacy of poplars as SRWCs. In the southeastern United States, such a study is greatly significant due to the physiographic variations in the region, which includes the Blue Ridge Mountains, the Piedmont, and the Coastal Plains, and the various growing conditions that can be considered for growing SRWCs. This information regarding clonal and genotypic adaptability to growing conditions and physiography can be applicable to eastern and southeastern states such as Pennsylvania, Maryland, Virginia, Tennessee, North Carolina, South Carolina, and Georgia, which have the mountain-Piedmont-coastal physiographic variations.

The objectives of this study were to examine how physiography, topography, and growing conditions in the southeastern USA can affect the adaptability and green wood biomass (hereafter biomass) of poplars, and whether poplar wood properties and composition vary due to position on tree stem, clone effect, and physiography. The following hypotheses were formulated:

1. The woody biomass proportions of stem and branches, the allometry between dimensions (height and stem diameter), and the woody biomass of poplars are affected by sites and clones.

2. The biomass productivity rankings of poplar clones are affected by physiography.

3. The biomass productivity rankings and adaptability of poplars (within a physiographic region) are affected by growing conditions including the marginality of lands, soil preparation, topographic positions (upslope versus downslope), and aspects of the land.

4. The density, moisture content, and carbon and nitrogen concentrations of the wood of poplars are affected by site, clones, and position on trees (basal, breast height, top). 


\section{Materials and Methods}

\subsection{Description of the Study Sites}

The study sites were located in North Carolina, and represented three physiographic provinces present in the eastern and southeastern USA, namely the Coastal Plains, the Piedmont, and the Blue Ridge Mountains (Table 1). The main physiographic feature of this study was altitude. Furthermore, four weather-related site variables were studied: Growing degree days (GDD) using $10{ }^{\circ} \mathrm{C}$ as a base temperature, total amount of precipitation and irrigation, Penman-Montheith reference evapotranspiration $\left(\mathrm{ET}_{\mathrm{o}}\right)$, and photosynthetically active radiation (PAR). GDD and $\mathrm{ET}_{\mathrm{o}}$ increased as the altitudes of the physiographic regions decreased. The totals of GDD, precipitation and irrigation, $\mathrm{ET}_{\mathrm{O}}$, and PAR at the sites for the 4-year study are presented in Figure 1.

Table 1. Details of the locations, physiography, and growing conditions of the sites where stands used for the biomass sampling and growth monitoring of poplar trees were located.

\begin{tabular}{|c|c|c|c|c|c|}
\hline $\begin{array}{l}\text { Site; Altitude (m, } \\
\text { above Sea Level) }\end{array}$ & Latitude; Longitude & Physiography & $\begin{array}{l}\text { Precipitation; } \\
\text { Irrigation (mm } \\
\left.\text { year }^{-1}\right)\end{array}$ & Soil Texture & Planted \\
\hline Salisbury (SB); 215 & $35.6974 ;-80.6219$ & Piedmont & 1118 & Loam & 2014 \\
\hline Mills River (MR); 630 & $35.4272 ;-82.5589$ & $\begin{array}{l}\text { Lower southern Blue } \\
\text { Ridge Mountains }\end{array}$ & 1261 & Loam & 2014 \\
\hline $\begin{array}{l}\text { Laurel Springs (LS); } \\
975\end{array}$ & $36.4023 ;-81.2971$ & $\begin{array}{l}\text { Upper southern Blue } \\
\text { Ridge Mountains }\end{array}$ & 1244 & $\begin{array}{c}\text { Sandy clay } \\
\text { loam }\end{array}$ & 2014 \\
\hline Williamsdale (WD); 26 & $34.7641 ;-78.0983$ & & 1400 & Loam & 2013 \\
\hline Gibson (GB); 76 & $34.7672 ;-76.5962$ & Coastal Plain & $1300 ; 1102$ & Loamy sand & 2013 \\
\hline Tidewater (TW); 5 & $35.8555 ;-76.6508$ & & $1200 ; 550$ & Loam & 2014 \\
\hline
\end{tabular}

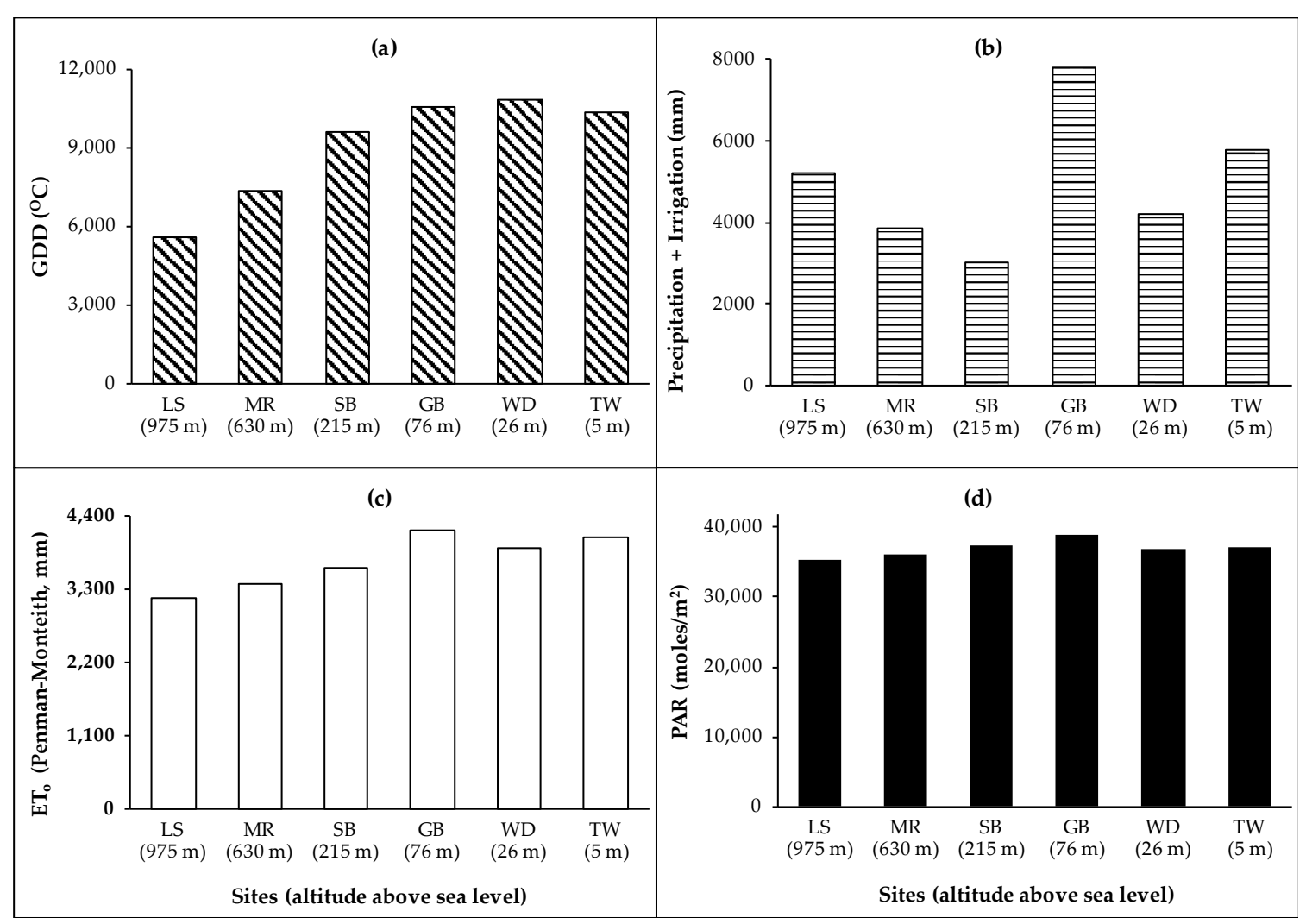

Figure 1. Totals of (a) growing degree days (GDD) based on a base temperature of $10{ }^{\circ} \mathrm{C}$, (b) precipitation and irrigation, (c) Penman-Montheith reference evapotranspiration, and (d) photosynthetically active radiation (PAR) at the sites during the 4-year study. 
The clones, genomic groups, and experimental designs used for the current study are presented in Table 2. Site preparation entailed weed control using mowers and post-emergent (Gly Star®Pro, Albaugh, INC., Ankeny, IO 50021, USA) and pre-emergent (Pendulum ${ }^{\circledR} 3.3$ EC Herbicide, BASF Corporation, Research Triangle Park, NC 27709, USA) herbicides, and subsoiling using a V-Ripper. Trees were planted in early spring as 30-cm-long cuttings. Prior to planting, the cuttings were immersed in water for 48 hours. Post-establishment weed control at all study sites entailed banding as needed with Gly Star®Pro along tree rows and mowing as needed between tree rows.

Table 2. Details of the experimental design, clones, and genomic grouping used for the study of the effects of physiography and growing conditions on poplar woody productivity, biomass allocation, and wood properties and composition. At Salisbury, three separate trials were used: SBC (randomized block design or RBD) with a 2500-tree/ha density, and SBS2 $\times 1$ (CRD) and SBS2 $\times 2$ (CRD) with 5000-tree/ha and 2500-tree/ha densities, respectively. Two separate LS trials were used: LS2 $\times 2$ with a 2500-tree/ha density and LS1 $\times 1$ with a 10,000-tree/ha density. WDD and WDSS denote disking and subsoiling treatments of soil preparation used at Williamsdale, respectively. Gibson (GB) and Williamsdale (WD) had the same clones and design details.

\begin{tabular}{|c|c|c|c|}
\hline Study & ffects and Stands (Trees per ha) & Genomic Groups (Clones) & Design \\
\hline \multirow{3}{*}{ Physiography } & $\begin{array}{l}\text { MR (lower Blue Ridge Mountains, 2500); } \\
\text { SBC (Piedmont, 2500) }\end{array}$ & $\begin{array}{l}\text { DD }(140,177,210,373,379) \\
\text { TD }(185,187,188,229,302,339,342,5077)\end{array}$ & RBD \\
\hline & $\begin{array}{l}\text { TW (Coastal, 5000); SBS2 } \times 1 \text { (Piedmont, } \\
\text { 5000) }\end{array}$ & DD $(140,312,356) ;$ TD $(187,188,302,342)$ & \multirow{5}{*}{ CRD } \\
\hline & $\begin{array}{l}\text { LS2 } \times 2 \text { (upper Blue Ridge Mountains, } \\
2500) \text {, SBS2 } \times 2 \text { (Piedmont, 2500); WD } \\
\text { (coastal, } 1495)\end{array}$ & DD $(140,176,356) ;$ TD $(185,187,188,229)$ & \\
\hline \multirow{3}{*}{$\begin{array}{l}\text { Growing } \\
\text { Conditions }\end{array}$} & $\begin{array}{l}\text { Land marginality (coastal, 1495): WD vs } \\
\text { GB }\end{array}$ & $\begin{array}{l}\text { DD }(140,176,356,373) ; \text { DM }(230) \text {; } \\
\text { TD }(185,187,188,229,339)\end{array}$ & \\
\hline & $\begin{array}{l}\text { Soil preparation (coastal, 1495): WDD, } \\
\text { WDSS }\end{array}$ & $\begin{array}{l}\text { DD }(140,176,356,373) ; \text { DM }(230) \text {; } \\
\text { TD }(185,187,188,229,339)\end{array}$ & \\
\hline & $\begin{array}{l}\text { Land topography and aspect (upper Blue } \\
\text { Ridge Mountains, 10,000): LS1 } \times 1 \text { (upper } \\
\text { Blue Ridge Mountains) }\end{array}$ & $\begin{array}{l}\text { DD }(176,210,312,356,373,379,419,426,443) ; \\
\text { TD (185, 187, 188, 229, 339, 342); } \\
\text { DM (230); DN (DN-34, OP-367) }\end{array}$ & \\
\hline
\end{tabular}

RBD: Randomized block design; CRD: Cluster randomized design; D: Populus deltoids; T: Populus trichocarpa; M: Populus maximowiczii; N: Populus nigra.

\subsection{Data Collection}

Tree height and stem diameter at breast height (DBH), which is $1.3 \mathrm{~m}$ above the soil surface, of all trees at the study sites were measured at the end of fourth year of growth. Whole-tree destructive sampling was carried out in March and April 2016 on 3-year-old trees representing small, medium, and large trees of clones 140, 187, and 188 from stands at Salisbury (SB) in the Piedmont, Mills River (MR) in the lower southern Blue Ridge Mountains, and Laurel Springs (LS) in the upper southern Blue Ridge Mountains. These three clones were selected for destructive sampling because of their availability at almost all stands located in the above three physiographic regions, and the total number of sampled trees, 30, included 10 trees from each clone. The classification of the trees as small, medium, and large were clone- and site-specific. That is, at each site and for each clone, three size classes were formed based on the tree height measurements at the end of 2015, namely, the bottom third (small), the middle third (medium), and the top third (large). From these clone- and site-specific classes, one random tree per clone per class was harvested at LS and MR (a total of nine trees at each site); whereas four trees were randomly sampled per clone at SB, including one small, two medium, and one large tree (a total of 12 trees). Prior to cutting down the trees, stem diameters at breast height (DBHs) and total heights were measured. The total fresh biomass of the trees (wood and foliage) was determined using a scale mounted on a tall sling, ensuring that the samples being measured were fully suspended. After the total tree biomasses were determined, all leaves were removed, and the leafless samples were weighed to determine the total fresh wood biomasses. The tree stem biomass was determined by weighing 
tree stems after removing branches and twigs. Cross-sectional fresh wood samples $(5 \mathrm{~cm}$ high) were collected from the base, breast height, and two-thirds of tree height positions, and their weights were recorded. The samples were placed in air-tight containers and kept in a cool and dry place for further processing in the laboratory. The cross-sectional wood samples were oven-dried at $60{ }^{\circ} \mathrm{C}$ until constant masses were obtained. The samples were then sent to the Forest Genetics and Biological Laboratory of the US Forest Service-Southern Research Station located in the Research Triangle Park in North Carolina for the determination of wood density, wood moisture, and carbon and nitrogen contents (\%).

\subsection{Data Analyses}

A generalized linear model (GLM) analysis using Proc GLM of SAS [13] $(\alpha=0.05)$ was applied for analyzing woody biomass allocation to stems and branches and the elemental composition (carbon and nitrogen), moisture content, and density of the wood (Hypotheses 1 and 4). The GLM was applied due to its flexibility in handling error distribution models with both normal and non-normal distributions. Where there were significant interaction effects, Proc Slice (SAS) was applied to further examine if all clones had interaction effects, and to identify clones showing interactions and those that do not show interaction effects. Clone-specific, site-specific, and generalized (all-data) allometric equations were derived by plotting volume indices (height multiplied by DBH squared) of the sampled trees against the ratio of the destructively sampled fresh woody biomass and mean wood density obtained from the cross-sectional wood samples. An analysis of covariance (ANCOVA) was applied using Proc REG (SAS) to examine if the allometric equations were significantly different (Hypothesis 1). ANCOVA was used because it enables correlation analysis between independent and dependent variables while meeting the assumptions of linearity between the variables, normality and independence of error terms, and homogeneity of error variances. Based on the ANCOVA results, the generalized wood volume equation was used to estimate the green wood biomass of standing trees using the average wood density and the heights and DBHs of standing 4-year-old trees. The wood biomass estimates were used to examine and compare the effects of physiography, land, and growing conditions on poplar productivity and adaptability.

Biomass analyses entailed ranking the biomasses of clones at individual sites and examining how the rankings would change with changes in physiography and growing conditions. With the ranking-based assessment, it was possible to concentrate on the site and physiographic variables in question while avoiding errors that could arise from potential differences in confounding factors between sites. For each study, an additional comparison of percentage changes in the green wood biomass of common clones at the paired sites was added to examine productivity differences between the sites. For analyzing physiography effects on poplars, a non-parametric significance analysis known as the Kruskal-Wallis test was applied using the SAS procedure Proc NPAR1WAYS to the clonal comparisons or ranks of wood productivity as the normality conditions of some of the studies were not met. For analyzing the effects of growing conditions on poplars, the Proc GLM (SAS procedure) was applied and where interaction effects existed, while the Proc SLICE (SAS) was applied to check if the interaction effects were present at all levels of the interacting factors/treatments. The effects of land topographic positions and aspects on poplar wood biomass were examined using LS1 $\times 1$ (Table 2 ), which included three plots with mean slopes of $14 \%-14.7 \%$ and upslope and downslope topographic positions on each plot. The aspects of the plots were southerly aspect or south-facing slope ( $\mathrm{N}$ to $\mathrm{S}$ ), westerly aspect or west-facing slope (N47E to S47W), and southwesterly aspect or southwest-facing slope (N65E to S65W). The Proc GLM (SAS) was applied for analyzing the effects and, where there were interaction effects, the Proc SLICE (SAS) was applied to examine the presence of interactions at various levels of the interacting treatments/factors. 


\section{Results}

\subsection{Woody Biomass}

Based on the biomass sampling, woody biomass allocation to branches and stems was not significantly affected by clone, site (physiography), and clone-site interaction (Figure 2). Clonal $(p=0.3148)$, site $(p=0.2998)$, and clone-site interaction $(p=0.4334)$ effects on the correlation between volume and volume index $\left(\mathrm{H} \times \mathrm{DBH}^{2}\right)$ were insignificant. Hence, the following generalized equations were developed:

$$
\begin{aligned}
& \text { Volume }\left(\mathrm{m}^{3}\right)=\mathrm{H} \times \mathrm{DBH}^{2} \times 0.99185+0.00188 \quad\left(\mathrm{R}^{2}=0.94\right) \\
& \qquad \text { Biomass }(\mathrm{t})=\text { volume } \times \text { wood density } \times 0.001 \\
& \text { Green wood biomass }(\mathrm{kg})=408.31 \times \mathrm{H} \times \mathrm{DBH}^{2}-0.2883 \quad\left(\mathrm{R}^{2}=0.98\right) \\
& \text { Green wood biomass }(\mathrm{kg})=2656.7 \times \mathrm{DBH}^{2}-0.2923 \quad\left(\mathrm{R}^{2}=0.98\right)
\end{aligned}
$$

where volume and biomass denote the volume and the biomass of the green wood of poplars, the unit of $\mathrm{H}$ and $\mathrm{DBH}$ is meter $(\mathrm{m})$, and wood density $\left(\mathrm{kg} / \mathrm{m}^{3}\right)$ is the mean density of wood samples from all tree positions of all trees sampled.

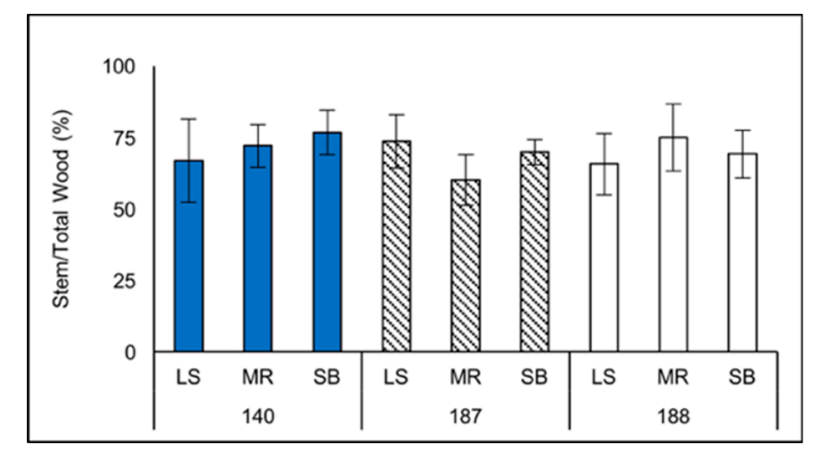

Figure 2. Biomass-based percentages of stem wood (from the total tree wood) for three sampled clones $(140,187$, and 188) sampled from stands located in the upper Blue Ridge Mountains (LS), the lower Blue Ridge Mountains (MR), and the Piedmont (SB) of North Carolina.

Green wood biomasses of all studied clones (Sections 2.3, 3.2 and 3.3) were estimated using Equations (1) and (2); direct estimations of poplar woody biomass using Equation (3) or Equation (4) were identical to biomass estimates obtained from Equations (1) and (2).

\subsection{The Effects of Physiography on Adaptability and Biomass Productivity}

Many of the studied sites showed an absence of significant clonal differences (at $p>0.05)$. However, differences in physiography led to some changes in the clonal rankings and significance of clonal differences. There were significant clonal differences in biomass at MR $(p=0.018)$ but not at SBC ( $p=0.1981)$, and there were differences in clonal standings between the sites (Figure 3a). The biomass of all studied clones was much higher at SBC than it was at MR. DD clones were affected by site changes to a much greater extent (approximately 1570\% to 5000\% increases) than TD clones (Figure 3b). Noting that only the GDD during the growth period was considerably higher at SBC than it was at $\mathrm{MR}$, it can be inferred that the biomass increases of the clones could mainly be attributed to better soil fertility at SBC. 


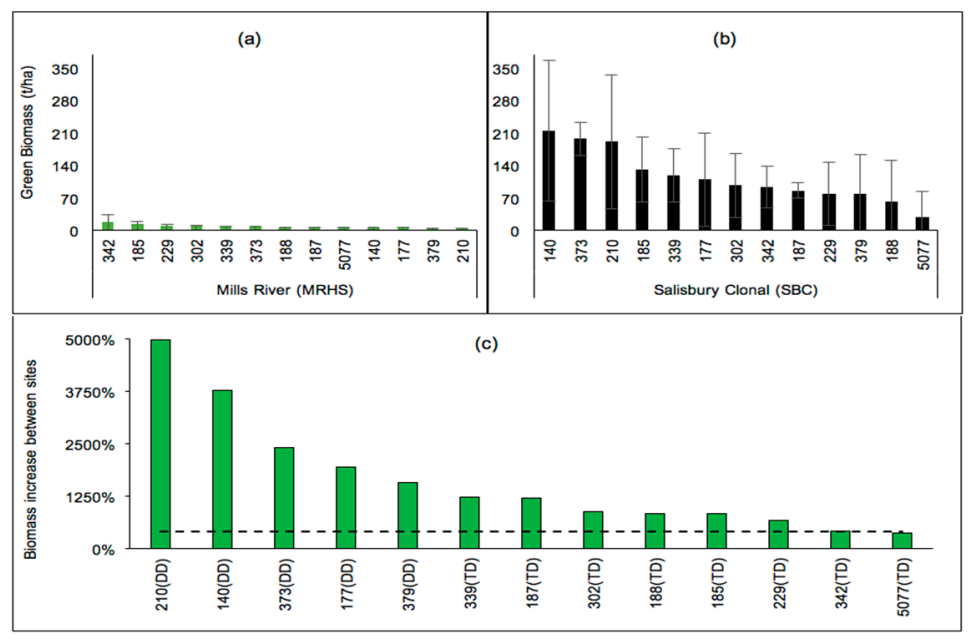

Figure 3. Four-year-old green wood biomass (tonne/ha) of non-irrigated poplars located in (a) the lower Blue Ridge Mountains (MR) and (b) the Piedmont (SBC), and (c) increases (\%) of clonal biomass at $\mathrm{SBC}$ relative to those at MR.

A comparison of poplars in the Piedmont (SBS2 $\times 1$ ) vs the Coastal Plain (Tidewater, $(\mathrm{TW}))$ with the same planting density (5000 trees/ha) showed that clonal biomass differences were significant at TW $(p<0.0001)$ but not at SBS2 $\times 1(p=0.0534)$. Regardless of the physiographic differences between the Piedmont (SBS2 $\times 1$ ) and the Coastal Plains (TW), and although the TW stand was irrigated, both SBS2 $\times 1$ and TW stands had common high-performing (140 and 356) and low-ranked clones (302 and 188) (Figure 4a). The TD clones showed biomass improvements at SBS2 $\times 1$ compared to those at TW, while DD clones showed increases or decreases to a lesser extent at SBS2 $\times 1$ compared to those at TW (Figure $4 \mathrm{~b}$ ). It should be noted that TW had considerably higher GDD and precipitation than SBS2 $\times 1$. It is also worth noting that the biomass increases of clone 140 were outstanding at lower-precipitation (irrigated) sites.

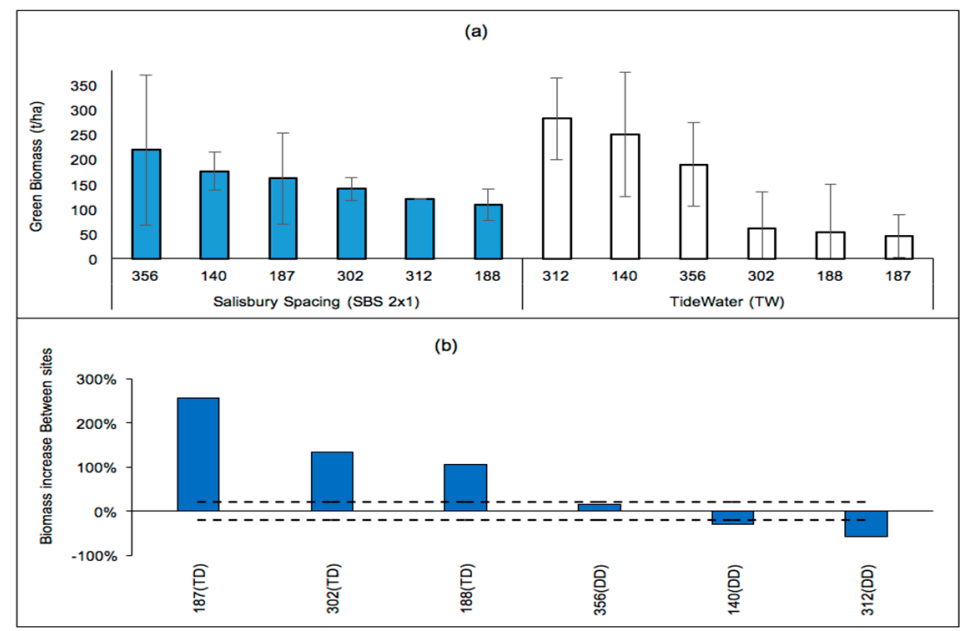

Figure 4. (a) Four-year-old green wood biomass ( $t / h a)$ of poplar stands located in the Piedmont (SBS2 $\times 1$, non-irrigated) and in the Coastal Plains (TW, irrigated) and (b) changes (\%) in clonal wood biomasses at SBS2 $\times 1$ relative to those at TW.

The clonal biomass differences were insignificant at LS2 $\times 2(p=0.1243), \operatorname{SBS} 2 \times 2(p=0.2451)$, and Williamsdale $(\mathrm{WD})(p=0.1193)$. The LS2 $\times 2$ and SBS2 $\times 2$ sites had common high-biomass clones $(229,185)$ and a low-producing clone $(187)$. Although TD clones were the highest producers at both sites, the clonal rankings changed between the sites (Figure 5a), with DD clones showing 
greater biomass increases at the Piedmont site (SBS2 $\times 2)$ than at the upper Mountain site $($ LS2 $\times 2)$, and TD clones showing variations within 20\% (Figure 5b). Most clones had similar productivities in LS2 $\times 2$ and SBS2 $\times 2$, and it can be inferred that the overall fertility of these sites may be similar. Irrespective of the possible fertility similarities of the sites, DD clones in general and clone 140 in particular showed greater increases in wood biomass at the sites where the GDD was higher even when the precipitation was lower. Some variations in clonal rankings also occurred between WD and SBS2 $\times 2$ (Figure 5a). Overall, tree growth was similar at the sites, while the per-hectare productivity was higher at SBS2 $\times 2$ due to the higher planting density. However, the selected weather-related variables (GDD, precipitation, and PAR) were higher at WD than those at SBS2 $\times 2$. The greatest growth increase $(75 \%-118 \%)$ at SBS2 $\times 2$ compared to that at WD was achieved by TD clones, while DD clones had a much lower proportional increase $(9 \%-45 \%)$. The clonal rankings were more definite at LS $2 \times 2$ than at WD, and there were changes in the rankings between the sites (Figure 5a). The higher precipitation at LS2 $\times 2$ may have contributed to the higher overall productivity at the site compared to that at WD. All clones that had higher productivity at LS2 $\times 2$ were TD, and all DD clones had greater biomass at WD (Figure 5b), which had a higher 4-year total GDD and lower precipitation.

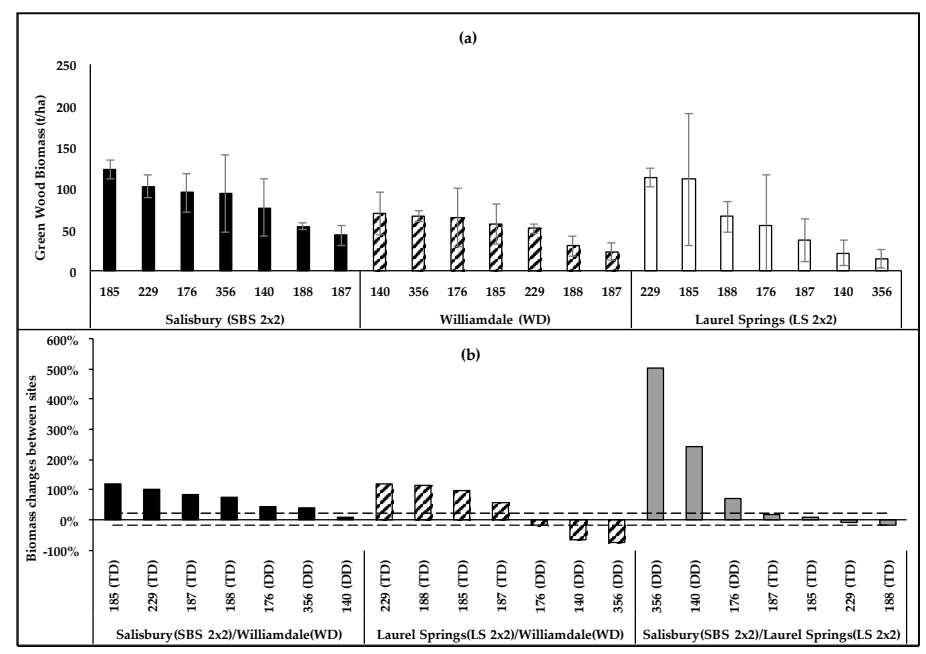

Figure 5. (a) Four-year-old green wood biomass ( $t / h a)$ of non-irrigated poplars located in the Piedmont (Salisbury, SBS2 $\times 2$ ) and the upper Blue Ridge Mountains (Laurel Springs, LS2 $\times 2$ ) and the Coastal $(\mathrm{WD})$ Plain; (b) clonal biomass changes (\%) at SBS2 $\times 2$ and LS2 $\times 2$ relative to those at WD, and at SBS2 $\times 2$ relative to those at LS2 $\times 2$.

\subsection{The Effects of Growing Conditions on Adaptability and Biomass Productivity}

Differences in the growing conditions led to some changes in the clonal rankings and significance of clonal differences of wood biomass productivity (at $p>0.05$ ). In the Coastal Plain, clonal differences in biomass were significant at Gibson (GB) $(p=0.03)$ but not at WD ( $p=0.0534)$. The biomass of all studied clones was much higher at the non-irrigated agricultural land at WD than at the irrigated marginal land at GB, with the exception of clones 187 and 339. The clonal ranking of biomass differed between the sites (Figure 6a), which could be due to fertility differences between the sites rather than any of the weather variables considered since none of these variables were higher at WD than they were at GB. The greatest growth responses (500\%-655\% increases) associated with changes in sites were experienced by all clones belonging to the DD genomic group with the TD clones showing $156 \%$ or less biomass increases at WD than at GB (Figure 6b). 


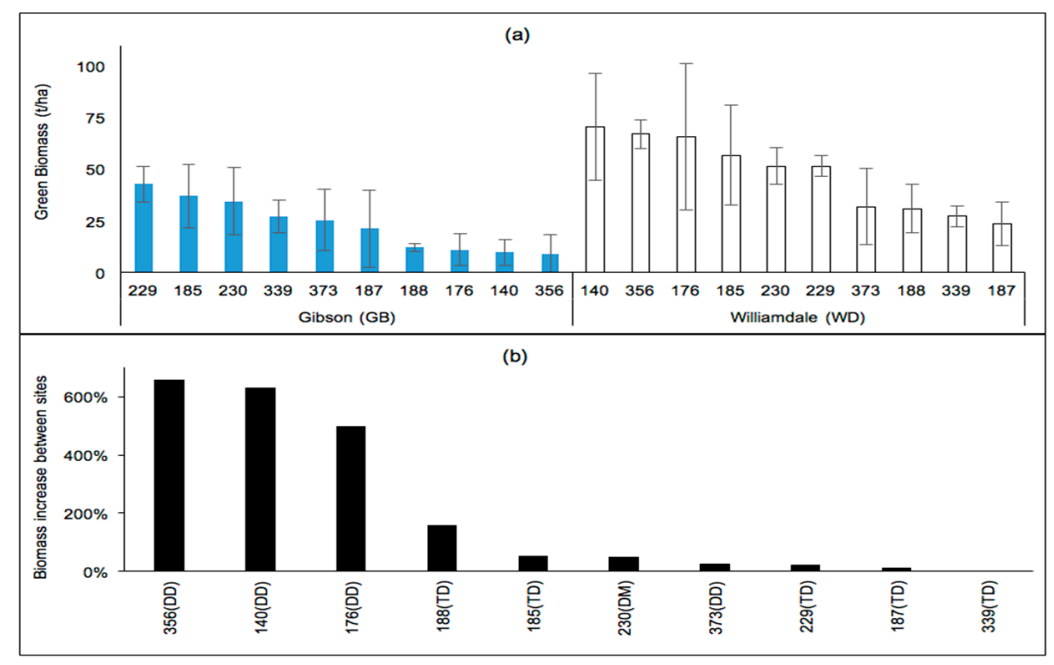

Figure 6. (a) Four-year-old green wood biomass (t/ha) of poplars located in the Coastal Plains under irrigated (GB) and non-irrigated (WD) conditions; (b) clonal biomass increases (\%) at WD relative to those at GB.

There were significant clonal differences in biomass in subsoiled plots (WDSS, $p=0.0091$ ) but not in disked plots (WDD, $p=0.3245$ ), as shown in Figure 7a. Overall, the average biomass was higher in WDSS (52 tonne/ha) than in WDD (43t/ha). Most clones produced significantly greater biomass (>20\%) in WDSS than in WDD, while the reverse was true for clone 187 (Figure 7b). With the exception of clone 339, biomass increases in WDSS compared to WDD were greater for DD clones than for TD clones.

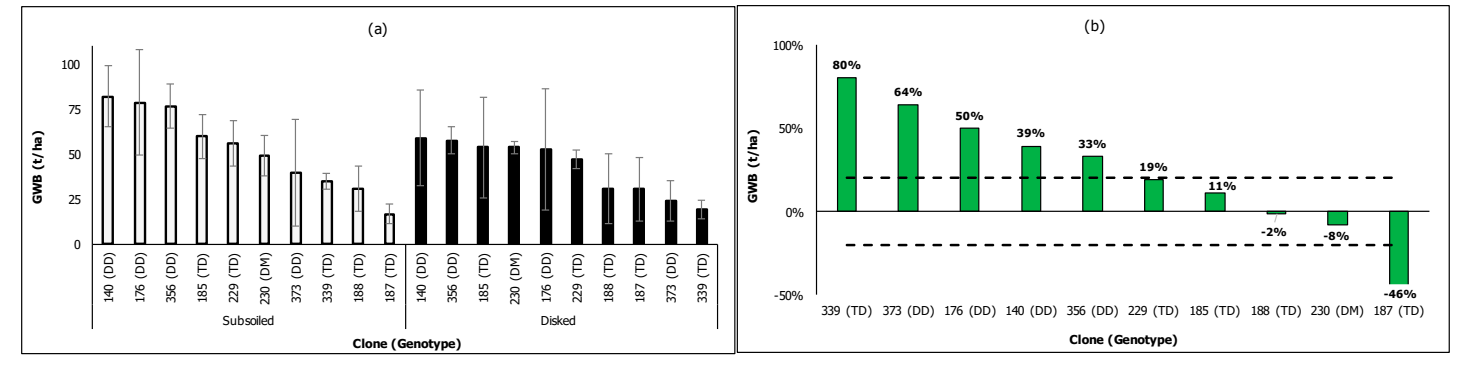

Figure 7. (a) Four-year-old green wood biomass ( $t /$ ha) of non-irrigated poplar stands in the coastal region (WD) using two soil preparation methods; (b) increases (\%) in clonal wood biomass at subsoiled plots (WDSS) relative to those at disked plots (WDD).

The results of the analysis of the effects of land topography and aspect on mean wood productivity of poplars (Figure 8) at clonal and genomic-group levels are presented in Table 3. The significance of the clone-aspect-position interaction effects was present for both upslope and downslope land positions and all land aspects, but not all clones showed the interaction effect. Clones 176, 419, 426, and 443, all of which belong to the DD genomic group, and clone DN-34 (DN) did not show interaction effects with the positions and aspects of the land. The genomic group-aspect interaction effect occurred in the southerly (south-facing) and the westerly (west-facing) plots but not in the southwest (SW)-facing plot, and was seen in TD and DM clones but not in DD and DN clones. The aspect-position interaction effect occurred in the SW-facing plot only while the interaction effect was present for both topographic positions. 


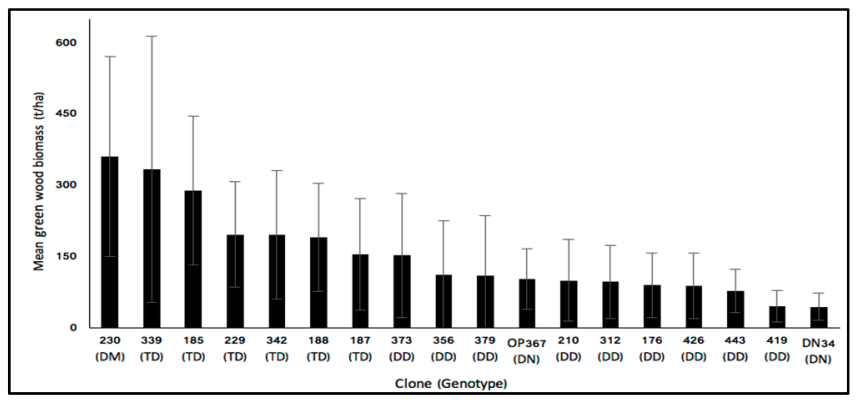

Figure 8. Mean green wood biomass ( $\mathrm{t} / \mathrm{ha})$ of high-density $(10,000$ trees/ha) and non-irrigated poplars after 4 years of growth at a study site in the upper Blue Ridge Mountains.

Table 3. Results of statistical analyses of the effects of topographic position (upslope vs. downslope) and aspect of the land as well as possible interactions with clones and genomic groups on the wood productivity of poplars.

\begin{tabular}{|c|c|c|c|c|c|}
\hline \multicolumn{3}{|l|}{ Clone } & \multicolumn{3}{|l|}{ Genomic Group } \\
\hline Clone & 52.2 & $<0.0001$ & Genomic group & 146.2 & $<0.0001$ \\
\hline Aspect & 70.7 & $<0.0001$ & Aspect & 65.1 & $<0.0001$ \\
\hline Clone-position interaction & 2.7 & 0.0002 & Genomic group-position interaction & 0.8 & 0.5137 \\
\hline Clone-aspect interaction & 15.2 & $<0.0001$ & Genomic group-aspect interaction & 26.3 & $<0.0001$ \\
\hline Clone-aspect-position interaction & 3.2 & $<0.0001$ & Genomic group-aspect-position interaction & 1.7 & 0.1083 \\
\hline
\end{tabular}

\subsection{Wood Properties and Composition}

\subsubsection{Wood Density}

Figure 9 presents the wood density of poplar clones based on samples obtained from various positions on the tree and from three sampling sites. The wood density was significantly affected by clone $(p<0.0001)$, site $(p<0.0001)$, position on trees $(p=0.0016)$, and clone-site interactions $(p=0.0356)$. The results of Proc Slice (SAS) show that the clone-site interaction effects were present for the three clones $(140,187$, and 188; $p \leq 0.0001)$, and at SB $(p<0.0001)$ and LS $(p=0.001)$ and but not at $\operatorname{MR}(p=0.2573)$.

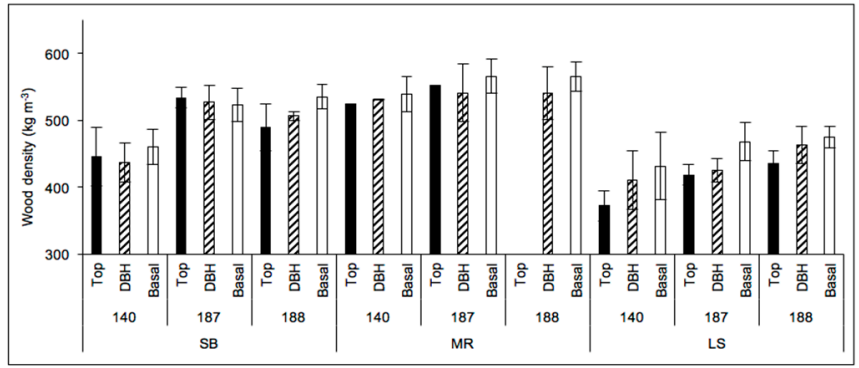

Figure 9. Wood densities $\left(\mathrm{kg} \mathrm{m}^{-3}\right)$ at various tree positions of three poplar clones (140, 187, and 188) from stands located in the Piedmont (SB), the upper Blue Ridge Mountains (LS), and the lower Blue Ridge Mountains (MR).

\subsubsection{Wood Composition}

The nitrogen content of the wood (\%) was significantly affected by site $(p=0.0105)$ and position on trees $(p<0.0001)$, but clonal differences were not significant $(p=0.2963)$ as shown in Figure 10a. The wood carbon content (\%), on the other hand, was significantly affected by site only 
$(p=0.0063)$. The wood moisture content was significantly affected by site $(p<0.0001)$, position on trees $(p<0.0001)$, and interaction effects including clone-site $(p=0.0002)$, site-position $(p=0.0098)$, clone-position $(p=0.0009)$, and clone-site-position $(p=0.0002)$ interactions. However, the clonal effect was insignificant in characterizing the variability in moisture content $(p=0.2819)$.

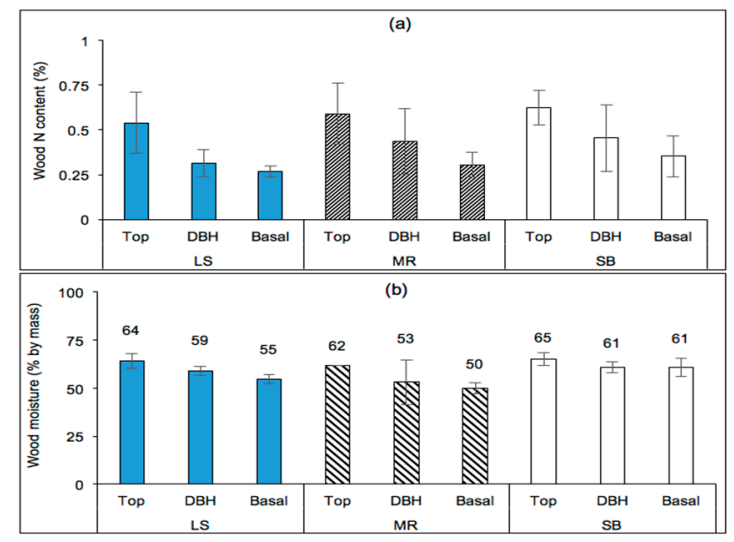

Figure 10. (a) Nitrogen content $(\mathrm{N}, \%)$ and $(\mathbf{b})$ moisture content by mass (\%) of poplar wood at various tree positions for three clones (140, 187, and 188) sampled from stands located in the Piedmont (SB), the upper southern Blue Ridge Mountains (LS), and the lower southern Blue Ridge Mountains (MR).

Based on the results of Proc Slice (SAS), the clone-position interaction effects were present for the three clones sampled $(140,187$, and 188; $p \leq 0.0100)$, especially at DBH $(p=0.0003)$ but not at the basal position $(p=0.3846)$. The site-position interaction effects were significantly present at the three sites (LS, $\mathrm{MR}$, and SB; $p \leq 0.0026)$ and at the basal tree position $(p \leq 0.0100)$, but were marginally significant for DBH position $(p=0.0582)$ and insignificant at the tree-top position $(p=0.5426)$. Clone-site interaction effects were significant for all sites $(p \leq 0.0114)$ and for clones 140 and $187(p<0.0001)$ but not for clone 188 ( $p=0.1847)$. In other words, the wood moisture content of clone 188 did not significantly vary among the sampled sites, and hence had no contribution to the clone-site interaction effects was reported. The clone-site-position interaction effects were present for all sites, positions (on tree), and clones.

\section{Discussion}

Several global studies have corroborated that the biomass productivity of poplars is greatly affected by clones and parentage [9,14-18]. Nevertheless, clonal rankings of wood volume after 1 year of growth in the upper southern Blue Ridge Mountains (LS) and the Piedmont (SB) were considerably different [11] from the 4-year woody productivity rankings of the current study. In another study, the height-based clonal ranks of 1-year-old poplar trees were not adequate indicators of rankings at medium and later stages of rotations [19]. For poplars, clonal survival after 1 year generally indicates a successful root development; yet, some clones suffer subsequent high mortality resulting from a lack of adaptability to growing conditions [6]. This leads to an overall decline in productivity on a per-area basis. The findings of the current study were in agreement with the results of Fortier et al. [4], indicating that poplar clonal differences in stem biomass were significant and that site had a greater effect on productivity.

A remarkable observation of the current study was regarding the response of genomic groups to changes in growing conditions. Improved growing conditions within the same physiography and physiographic differences between the Blue Ridge Mountains and the Piedmont prompted greater productivity increases from DD clones than from other genomic groups. Conversely, physiographic differences between the Coastal Plains and the Blue Ridge Mountains or the Piedmont and between the Piedmont and the Blue Ridge Mountains led to greater wood productivity increases from TD clones than from DD clones. Variations in productivity performances across different growing 
conditions for clones belonging to particular genomic groups were less definite, which generally agreed with the findings of Verlinden et al. [18], who stated that closely related genotypes are expected to have similar biomass productivities. Many studies have shown the strong effects of site on poplar growth and biomass productivity $[9,14,16,17,20-23]$. One study demonstrated strong effects of soil conditions and fertility on poplar biomass productivity [17], while another study emphasized that elevation and fertility of sites have stronger effects on poplar biomass productivity than clones [23]. Our result of biomass productivity performance of pure versus mixed hybrid poplars was contrary to the results of Reference [24], in which pure poplar species produced greater biomass than mixed poplar species when growing conditions were non-conducive. Benetka et al. $[25,26]$ found that mixed poplar species produced greater biomass than pure poplar species under sub-optimal site conditions, while differences in biomass between pure and mixed poplar species under conducive conditions were not significant. Moreover, other studies reported contradicting results, with one study reporting no clear biomass-based advantage of pure or mixed hybrid poplars [16], while others showed the superiority of interspecific hybrid poplars compared to pure hybrids on the basis of biomass productivity [27-29]. Although differences in water use have been observed among clones [30], poplars vary in water use efficiency (WUE) at the genotype level $[30,31]$, and the more distinctive productivity differences at the genomic-group level in the current study could possibly be WUE-related.

The current findings of woody biomass allocation (where clone, site, and interaction effects were insignificant) were in contrast with the results of a multi-clonal study of 6-year-old poplars [4]. Percentage allocations of wood biomass to stem and branches are likely to vary with different phases of tree growth. Wood biomass allocation can be used to identify less-branching clones preferable for high-end wood products, possibly due to the presence of fewer irregularities and lesser pruning required [4], and to identify suitable silvicultural practices in line with the purpose of the stands.

Although allometric equations were developed using destructively obtained data, the use of the equations enabled accurate, straightforward, and non-destructive estimations of the growth, biomass, and carbon storage of trees and forests using easily measurable variables [32]. The use of generalized equations to estimate green wood biomass in all current sites, including sites not used as data sources for developing the equations, is supportable by studies that reported most allometric relationships developed for the same species but different sites to be similar [33] and supported the use of equations developed for a species in a different place if site-specific or generalized equations for the species are not present [34]. In the current study, the addition of height as a predictor variable for estimating biomass did not improve the accuracy of the estimations. Hence, green woody biomass can be reliably estimated using only the DBH (Equation (4)), which is an important result since DBH is easy to measure. However, the DBH-only equation used in the work of Zalesny et al. [9] and references therein (wood biomass $=6.16-2.23 \mathrm{DBH}+0.353 \mathrm{DBH}^{2}$ ) provided biomass predictions that deviated significantly ( $p=0.0035, t_{0.05}=3.20$ ) from both the actual biomass sampled (from SB, MR, and LS) and the estimates of the allometric equations developed in the current study.

With the ranking-based analysis approach employed in this study, poplar productivity and adaptability to growing conditions was assessed as an outcome inclusive of variables that change with sites and physiography. This approach captured real-world planting conditions, including existing land marginality types and the variability and interactions of growth factors across growing and physiographic conditions. It was possible to concentrate on the site and physiographic variables in question with the paired-site approach. Nonetheless, some paired sites likely had different confounding factors, which makes isolating the effects of a particular growing condition on clones challenging. The poplars clones ranked as the highest biomass producers after 3 years are the clones that can be expected to have the highest biomass-based ranking after 10 growth years [6]. Biomass-based genotype rankings of poplars are also expected to be maintained beyond the first rotation [18]. Hence, our findings can be used to identify the best-adapting and highest-producing poplar clones and genomic groups for the duration of rotations under the studied and similar conditions. However, the woody biomass estimates presented should be interpreted bearing in mind that there is an inherent 
bias of overestimation associated with using trial-scale productivity to estimate productivity at a production scale [9].

Wood characteristics affect the processing and use of poplar wood. Wood density significantly differed among sampled sites of the current study, while Headlee et al. [10] reported significant wood density differences among sites at year 20 but not at year 10. Headlee et al. [10] also reported a poplar wood density of $267-495 \mathrm{~kg} / \mathrm{m}^{3}$ from their study and of $270-500 \mathrm{~kg} / \mathrm{m}^{3}$ from other studies (3- to 22-year-old trees). A mean wood density range of 300-390 g/ $\mathrm{cm}^{3}$ was also reported for North American natural forests including hybrid poplars [3]. In the current study, wood density, based on 80 samples from 30 trees representing three clones and three physiographic regions, had a wider range of $345-578 \mathrm{~kg} / \mathrm{m}^{3}$ (mean: $492 \pm 58 \mathrm{~kg} / \mathrm{m}^{3}$ ). Poplar wood is relatively weak in many strength criteria (tensile, compressive, shearing, etc.) but has high transverse strength and elasticity. Still, regional differences in these strength attributes can be significant [3]. Since a positive correlation exists between the wood density and the wood strength [35], poplar wood density differences between the current and the above studies are likely to have implications on wood strength. The processing and the use of poplar wood are also affected by properties related to wood water content. Due to its high water content, poplar wood is convenient for specialized cutting and shrinks by as much as $12 \%$ (by volume) when drying, although its shrinking pattern makes the wood prone to deformations [3].

There were three pest attacks by cottonwood leaf beetles (Chrysomela scripta F.) during the current study, early in the first and the second years of growth at the Piedmont site (SB) and early in the third year at one of the coastal sites (WD). Early detection of the insects and leaf damages and prompt treatment of the affected stands with SEVIN@Insect Killer Concentrate (GardenTech ${ }^{\circledR}$, Bayer CropScience LP, Research Triangle Park, NC 27709, USA) allowed leafing of the trees in time for summer. Leaf rust (caused by Melampsora medusae) often occurred toward the end of the growing seasons at all sites. Although a detailed study on poplar clonal vulnerability to the rust infections was not conducted, there seemed to be somewhat visible differences in the extent of the rust among some trees. However, there have not been any definite indications that poplar susceptibility or resistance to pests and diseases is affected by growing condition or physiography.

Based on the current and cited [6,36] studies, poplars have a great potential for the production of sustainable woody feedstocks, and their productivity and feasibility can be greatly enhanced provided that site-suitable genotypes and clones are selected. Optimum stand management is crucial for the feasibility of the species as an SRWC [6], and should include robust monitoring to prevent and minimize disease and pest damages. Finally, the economic feasibility of the clones studied cannot be realized under the current market conditions of smaller-diameter woody feedstocks and feedstock prices. However, optimally established and managed stands of site-suitable clones growing on productive sites could have positive economic returns at longer rotations ( $>7$ years) and lower feedstock prices ( $\$ 30 /$ ton) or at higher feedstock prices $(>\$ 36 /$ ton) and shorter rotations (5 years).

\section{Conclusions}

The green wood productivity, wood properties and composition, and wood biomass allocation of poplars were examined in relation to site conditions (fertility, irrigation, and soil preparation), physiography, and land topography (position and aspect). Although not all clonal differences in the wood biomass were significant, the clonal rankings and the significance of clonal differences were largely affected by growing conditions and physiography. Changes in poplar wood productivity due to physiography and growing conditions were more structured at the genomic-group level than at the clonal level. A higher-altitude physiography led to greater wood biomass increases in TD clones than in DD clones (compared to a lower-altitude physiography) and vice versa. Within a physiographic province, favorable growing conditions largely led to greater wood biomass productivity of DD clones than of TD and DM clones. No clear correlations were observed between poplar productivity and regional adaptability and weather-related variables (GDD, precipitation amount, reference evapotranspiration, and PAR). The aspect of the land affected the wood productivity of 
poplar genomic groups and clones significantly. The site significantly affected the wood properties and composition studied, while clonal effects on wood composition and clonal and site effects on wood biomass allocation and biomass-dimension allometric relationships were not significant. Although clones that showed greater biomass responses to growing conditions generally belonged to the same genomic group, clone-level selection could produce greater wood biomass gains than selections made at the genomic-group level.

Author Contributions: Conceptualization, methodology \& investigation: S.B.G., E.G.N. and D.W.H.; Data curation, formal analysis, validation \& original draft preparation: S.B.G.; Resources (wood analyses): C.A.M.; Funding acquisition: E.G.N. and D.W.H.; Supervision \& project administration: D.W.H., E.G.N. and S.B.G.; Reviewing \& editing: S.B.G., E.G.N., D.W.H. and C.A.M.

Funding: This research was funded by the North Carolina Department of Agriculture and Consumer Services, Bioenergy Research Initiatives (NCDA\&CS-BRI), grant numbers: G40100278914RSD and G40100278314RSD.

Acknowledgments: We would like to thank the NCDA\&CS-BRI (formerly the Biofuels Center of North Carolina) for funding, and Arborgen, LLC, and GreenWood Resources for their technical support and for supplying trees. We are also grateful to the NCDA\&CS research stations at the study sites and the Town of Gibson, North Carolina for their cooperation and assistance at the study sites, and to Karen Sarsony from the US Forest Service, Southern Research Station for her analysis of the wood samples used for the current study.

Conflicts of Interest: The authors declare no conflict of interest.

\section{References}

1. U.S. Department of Energy. 2016 Billion-Ton Report: Advancing Domestic Resources for a Thriving Bioeconomy. In Economic Availability of Feedstocks; Langholtz, M.H., Stokes, B.J., Eaton, L.M., Eds.; ORNL/TM-2016/160; Oak Ridge National Laboratory: Oak Ridge, TN, USA, 2016; Volume 1, 448p. [CrossRef]

2. U.S. Energy Information Administration (EIA), Independent Statistics and Analysis. Wood and Wood Waste: Energy Explained, Your Guide to Understanding Energy. 2018. Available online: https:/ /www.eia.gov / energyexplained /index.php?page=biomass_wood (accessed on 18 August 2018).

3. Balatinecz, J.J.; Kretschmann, D.E.; Leclercq, A. Achievements in the utilization of poplar wood-Guideposts for the future. For. Chron. 2001, 77, 265-269. [CrossRef]

4. Fortier, J.; Gagnon, D.; Truax, B.; Lambert, F. Biomass and volume yield after 6 years in multiclonal hybrid poplar riparian buffer strips. Biomass Bioenergy 2010, 34, 1028-1040. [CrossRef]

5. Berthelot, A.; Ranger, J.; Gelhaye, D. Nutrient uptake and immobilization in a short-rotation coppice stand of hybrid poplars in North-West France. For. Ecol. Manag. 2000, 128, 167-179. [CrossRef]

6. Kaczmarek, D.J.; Coyle, D.R.; Coleman, M.D. Survival and growth of a range of Populus clones in central South Carolina USA through age ten: Do early assessments reflect longer-term survival and growth trends? Biomass Bioenergy 2013, 49, 260-272. [CrossRef]

7. Stanturf, J.A.; van Oosten, C.; Netzer, D.A.; Coleman, M.D.; Portwood, C.J. Ecology and silviculture of poplar plantations. In Poplar Culture in North America; Dickmann, D.I., Isebrands, J.G., Eckenwalder, J.E., Richardson, J., Eds.; NRC Research Press, National Research Council of Canada: Ottawa, ON, Canada, 2001; Part A, Chapter 5; pp. 153-206.

8. Lo, M.H.; Abrahamson, L.P. Principal component analysis to evaluate the relative performance of nine-year-old hybrid poplar clones. Biomass Bioenergy 1996, 10, 1-6. [CrossRef]

9. Zalesny, R.S.; Richard, B.H.; Zalesny, J.A.; McMahon, B.G.; Berguson, W.E.; Stanosz, G.R. Biomass and genotype $\times$ gnvironment interactions of Populus energy crops in the Midwestern United States. BioEnergy Res. 2009, 2, 106-122. [CrossRef]

10. Headlee, W.L.; Zalesny, R.S., Jr.; Hall, R.B.; Bauer, E.O.; Bender, B.; Birr, B.A.; Miller, R.O.; Randal, J.A.; Wiese, A.H. Specific gravity of hybrid poplars in the North-Central Region, USA: Within-tree variability and site $\times$ genotype effects. Forests 2013, 4, 251-269. [CrossRef]

11. Ghezehei, S.B.; Nichols, E.G.; Hazel, D.W. Early clonal survival and growth of poplars grown on North Carolina Piedmont and Mountain marginal lands. BioEnergy Res. 2016, 9, 548-558. [CrossRef]

12. Shifflett, S.D.; Hazel, D.W.; Frederick, D.J.; Nichols, E.G. Species trials of short rotation woody crops on two wastewater application sites in North Carolina, USA. BioEnergy Res. 2014, 7, 157-173. [CrossRef] 
13. SAS 9.4 for Windows x64 Based Systems. Available online: https://ualberta.onthehub.com/WebStore/ OfferingDetails.aspx?o=56e487ad-057e-e311-93f9-b8ca3a5db7a1 (accessed on 30 January 2019).

14. Pliura, A.; Zhang, S.Y.; MacKay, J.; Bousque, J. Genotypic variation in wood density and growth traits of poplar hybrids at four clonal trials. For. Ecol. Manag. 2007, 238, 92-106. [CrossRef]

15. Guo, X.; Zhang, X. Performance of 14 hybrid poplar clones grown in Beijing, China. Biomass Bioenergy 2010, 34, 906-911. [CrossRef]

16. Nielsen, U.B.; Madsen, P.; Hansen, J.K.; Nord-Larsen, T.; Nielsen, A.T. Production potential of 36 poplar clones grown at medium length rotation in Denmark. Biomass Bioenergy 2014, 64, 99-109. [CrossRef]

17. Pliura, A.; Suchockas, V.; Sarsekova, D.; Gudynaite, V. Genotypic variation and heritability of growth and adaptive traits, and adaptation of young poplar hybrids at northern margins of natural distribution of Populus nigra in Europe. Biomass Bioenergy 2014, 70, 513-529. [CrossRef]

18. Verlinden, M.S.; Broeckx, L.S.; Ceulemans, R. First vs. second rotation of a poplar short rotation coppice: Above-ground biomass productivity and shoot dynamics. Biomass Bioenergy 2015, 73, 174-185. [CrossRef]

19. Brown, K.R.; Beall, F.D.; Hogan, G.D. Establishment-year height growth in hybrid poplars; Relations with longer-term growth. New For. 1996, 12, 175-184.

20. Riemenschneider, D.E.; Berguson, W.E.; Dickmann, D.I.; Hall, R.B.; Isebrands, J.G.; Mohn, C.A.; Stanosz, G.R.; Tuskan, G.A. Poplar breeding and testing strategies in the North-Central U.S.: Demonstration of potential yield and consideration of future research needs. For. Chron. 2001, 77, 245-253. [CrossRef]

21. Pliura, A.; Zhang, S.Y.; Bousquet, J.; MacKay, J. Age trends in variation of wood density and its intra-ring components of young poplar hybrid crosses. Ann. For. Sci. 2006, 63, 673-685. [CrossRef]

22. Dillen, S.Y.; Marron, N.; Bastien, C.; Ricciotti, L.; Salani, F.; Sabatti, M.; Pinel, M.P.C.; Rae, A.M.; Taylor, G.; Ceulemans, R. Effects of environment and progeny on biomass estimations of five hybrid poplar families grown at three contrasting sites across Europe. For. Ecol. Manag. 2007, 252, 12-23. [CrossRef]

23. Traux, B.; Cagnon, D.; Fortier, J.; Lambert, F. Yield in 8-year-old hybrid poplar plantations on abandoned farmland along climatic and soil fertility gradients. For. Ecol. Manag. 2012, 3, 228-239. [CrossRef]

24. Dillen, S.; Djomo, S.N.; Al Afas, N.; Vanbeveren, S.; Ceulemans, R. Biomass yield and energy balance of a short-rotation poplar coppice with multiple clones on degraded land during 16 years. Biomass Bioenergy 2013, 56, 157-165. [CrossRef]

25. Benetka, V.; Bartáková, I.; Mottl, J. Productivity of Populus nigra L. ssp. nigra under short-rotation culture in marginal areas. Biomass Bioenergy 2002, 23, 327-336. [CrossRef]

26. Benetka, V.; Novotná, K.; Štochlová, P. Biomass production of Populus nigra L. clones grown in short rotation coppice systems in three different environments over four rotations. iForest 2014, 7, 233-239. [CrossRef]

27. Heilman, P.E.; Ekuan, G.; Fogle, D. Above- and below-ground biomass and fine roots of 4-year-old hybrids of Populus trichocarpa $\times$ Populus deltoides and parental species in short-rotation culture. Can. J. For. Res. 1994, 24, 1186-1192. [CrossRef]

28. Ceulemans, R.; Deraedt, W. Production physiology and growth potential of poplars under short-rotation forestry culture. For. Ecol. Manag. 1999, 121, 9-23. [CrossRef]

29. Verlinden, M.S.; Broeckx, L.S.; Van den Bulcke, J.; Van Acker, J.; Ceulemans, R. Comparative study of biomass determinants of 12 poplar (Populus) genotypes in a high-density short-rotation culture. For. Ecol. Manag. 2013, 307, 101-111. [CrossRef]

30. Jones, T.; McIvor, I.; McManus, M. Drought tolerance and water-use efficiency of five hybrid poplar clones. In Integrated Nutrient and Water Management for Sustainable Farming; Currie, L.D., Singh, R., Eds.; Occasional Report No. 29; Fertilizer and Lime Research Centre, Massey University: Palmerston North, New Zealand, 2016; pp. 1-13. Available online: http:/ / flrc.massey.ac.nz/publications.html (accessed on 24 August 2018).

31. Rancourt, G.T.; Éthier, G.; Pepin, S. Greater efficiency of water use in poplar clones having a delayed response of mesophyll conductance to drought. Tree Physiol. 2015, 35, 172-184. [CrossRef]

32. Ghezehei, S.B.; Annandale, J.G.; Everson, C.S. Shoot allometry of Jatropha curcas. South. For. 2009, 71, $279-286$. [CrossRef]

33. Tritton, L.M.; Hornbeck, J.W. Biomass estimation for Northeastern forests. Ecol. Soc. Am. Bull. 1981, 62, 106-107.

34. Pastor, J.; Abet, J.D.; Melillo, J. Biomass prediction using generalized allometric regressions for some northeast tree species. For. Ecol. Manag. 1984, 7, 265-274. [CrossRef] 
35. WoodProdcuts.fi. Strength Properties of Wood. Wood Products. 13 November 2013. Available online: https://www.woodproducts.fi/content/wood-a-material-1 (accessed on 9 August 2018).

36. Zalesny, R.S.; Deahn, D.M.; Coyle, D.R.; Headlee, W.L. An approach for siting poplar energy production systems to increase productivity and associated ecosystem services. For. Ecol. Manag. 2012, 284, 45-58. [CrossRef] 